\title{
Environmentally friendly inhibitor of the corrosion of mild steel: Commercial oil of Eucalyptus
}

\author{
B. Hafez, ${ }^{1}$ M. Mokhtari, ${ }^{2}$ H. Elmsellem ${ }^{3} *$ and H. Steli ${ }^{4}$ \\ ${ }^{I}$ Department of Chemistry, College of Sciences, University of Sharjah, PO Box: 27272, \\ $U A E$ \\ ${ }^{2}$ Laboratory of Valorization and Technology of Saharian Resources (VTRS), Faculty of \\ Technology, Hamma Lakhdar University, 39000, Algeria \\ ${ }^{3}$ Laboratory of Applied Analytical Chemistry, Materials and Environment, Faculty of \\ Science, B.P. 717, 60000 Oujda, Morocco \\ ${ }^{4}$ Mechanical \& Energy Laboratory, Faculty of Sciences, Mohammed Premier University, \\ Oujda, Morocco \\ *E-mail: h.elmsellem@gmail.com
}

\begin{abstract}
A study assessing plant extracts as green corrosion inhibitors is important because of the potential cost effective and environmental benefits. This study employed a strategy to evaluate the effectiveness these molecules against corrosion of mild steel in acid media. Many plant extracts have been used as corrosion inhibitors of iron or steel in acidic media. This research aims to examine the effects of commercial oil of Eucalyptus on inhibition of corrosion with mild steel in hydrochloric acid by means of gravimetric, potentiodynamic polarization and electrochemical impedance spectroscopic measurements. The results of the polarization curves show that the corrosion current density decreases from $3618 \mu \mathrm{A} / \mathrm{cm}^{2}$ to $87 \mu \mathrm{A} / \mathrm{cm}^{2}$ with the addition of the Eucalyptus inhibitor. The charge transfer resistance increases from $17 \mathrm{Ohm} \cdot \mathrm{cm}^{2}$ to $185 \mathrm{Ohm} \cdot \mathrm{cm}^{2}$ in the electrochemical impedance spectrum after the addition of the oil Eucalyptus inhibitor in the more concentrated solutions It is found that the adsorption of our green inhibitor on steel surface obeys the Langmuir adsorption isotherm equation. The inhibition efficiency was found to be increased with increasing immersion time of samples in the solution. The polarization plots indicate that the studied Eucalyptus inhibitor affects both the anodic metal dissolution, and the catholic hydrogen evolution acting as a mixed type inhibitor.
\end{abstract}

Keywords: Eucalyptus, commercial oil, inhibition, corrosion, mild steel, green inhibitor.

Received: June 30, 2019. Published: July 31, 2019

doi: $\underline{10.17675 / 2305-6894-2019-8-3-8}$ 


\section{Introduction}

Corrosion is a natural process, which converts a refined metal to a more chemically-stable form, such as its oxide, hydroxide, or sulfide. It is the gradual destruction of materials (usually metals) by chemical and/or electrochemical reaction with their environment. Corrosion engineering is the field dedicated to controlling and stopping corrosion [1-5].

Even though most of the materials such as ceramics and glass also decay, usually, the term corrosion is concerned with metals. Corrosion is a natural process, spontaneous and thermodynamically stable process favored by nature [6-10].

So no one can prevent corrosion. However the rate of corrosion can be controlled, just like postponing death.

There are many methods to control corrosion such the use of inhibitors in small quantities is a common process. Once organic compounds were used as corrosion inhibitors effectively. Yet, environmental scientists point out the health hazards caused by organic compounds. Hence corrosion scientists go for environmentally friendly non-toxic natural products extracts as corrosion inhibitors [11-13].

Many parts of plant materials such as bark, seeds, flowers and leaves can be used as corrosion inhibitors. Several research studies have been published on this subject [14-16].

In the meaning of expanding green and environmentally friendly inhibitors and further research into the activity of plants oils in different fields, we report the applicability of oil Eucalyptus as an efficient and green inhibitor for mild steel in $\mathrm{HCl}$ solution by using electrochemical impedance spectroscopy (EIS), gravimetric and polarization resistance analyses.

In the present study, the inhibitive effect of oil Eucalyptus on corrosion of mild steel in hydrochloric acid solution $(1 \mathrm{M} \mathrm{HCl})$ was investigated using weight loss, potentiodynamic polarization and electrochemical impedance spectroscopy (EIS) methods.

\section{Experimental}

\section{II.1. Plant material}

Kingdom: Plantae

There are more than 800 species of eucalyptus and most are native to Australia; a very small number are found in adjacent areas of New Guinea and Indonesia. One species, Eucalyptus deglupta, ranges as far north as the Philippines. Of the 15 species found outside Australia, just nine are exclusively non-Australian. Species of eucalyptus are cultivated widely in the tropical and temperate world, including the Americas, Europe, Africa, the Mediterranean Basin, the Middle East, China and India. However, the range over which many eucalypts can be planted in the temperate zone is constrained by their limited cold tolerance. 


\section{II.2. Anticorrosion effects}

\section{II.2.1. Materials}

Tests were performed on cold rolled steel (CRS) with a composition of $0.09 \% \mathrm{P} ; 0.38 \% \mathrm{Si}$; $0.01 \% \mathrm{Al} ; 0.05 \% \mathrm{Mn} ; 0.21 \% \mathrm{C} ; 0.05 \% \mathrm{~S}$ and the remainder iron. The materials were polished with emery paper up to grade 1200, washed thoroughly with doubly-distilled water, degreased with AR grade ethanol and acetone, and dried at room temperature.

MS samples of $1.0 \times 1.0 \times 0.5 \mathrm{~cm}$ and MS powder were used for weight loss studies. For electrochemical studies, specimens with an exposed area of $1 \mathrm{~cm}^{2}$ were used. These specimens were degreased ultrasonically with 2-propanol and polished mechanically with different grades of emery paper to obtain very smooth surfaces.

\section{II.2.2. Preparation of the solutions}

The test solutions were prepared by dilution with analytical grade $37 \% \mathrm{HCl}$ with distilled water.

The inhibitor was dissolved in the acid solution at the required concentrations (mol/L) and the solution in the absence of the inhibitor was taken as blank for comparison purposes.

Experiments were conducted on several occasions to ensure reproducibility. Concentrations of inhibitor were $0.25,0.5$, and $1 \mathrm{~g} / \mathrm{L}$.

\section{II.2.3. Electrochemical measurements}

Testing of potential free and spectroscopy electrochemical impedance (EIS) was performed using a potentiostat PGZ 301 (Radiometer Analytical) controlled by the VoltaMaster 4 software. This assembly comprises three electrodes: steel as a working electrode (ET), platinum as a counter electrode $(\mathrm{CE})$, and $\mathrm{Ag} / \mathrm{AgCl}$ as a reference electrode.

\section{Results and discussion}

\section{III.1. Oil composition of Eucalyptus}

The GC-MS result of Eucalyptus oil showed that the sample consist of 22 components, representing $98.80 \%$ of the total components identified (Table 1). The major phytochemicalin the oil were: palmitic acid (29.00\%), oleic acid (10.00\%), E,E,E- $\alpha$ springene (9.00\%), 2-ethenyl-2,5-dimethyl-4-hexen-1-ol (8.00\%), 2,4-dimethylheptane (6.00\%), hexahydrofarnesyl acetone (5.0\%), geranylbutanoate $(4.00 \%)$, farnesol $(4.00 \%)$, geranylgeraniol $(4.00 \%)$ and trans-2-methyl-2-(4-methyl-3-pentenyl)-cyclopropanecarboxaldehyde $(4.00 \%)$. 
From the GC-MS analysis, it appears that the composition of commercial oil of Eucalyptus.

Table 1: Chemical composition of Eucalyptus oil.

Compound

2,4-Dimethylheptane

$\alpha$-Pinene

-Cymene

1,8-Cineole

Phthalic acid, di(1-hexen-5-yl) ester

Palmitic acid

Oleic acid

Geranyl butanoate

Hexahydrofarnesyl acetone

2,4-Dibromopentane

2,4-Dimethyl-2,4-heptadiene

Levomenol

$E, E, E-\alpha-$ Springene

2-Ethenyl-2,5-dimethyl-4-hexen-1-ol

5-Bromo- $n$-pentanol-cyclohexyl ether

threo-2,3-Dibromopentane

Farnesol

Lavandulol

1,1'-Bicyclooctyl

Geranylgeraniol

$(E, E)$-Geranyl linalool
Percentage Composition

6.0

4.0

0.4

0.5

1.0

29.0

10.0

4.0

5.0

0.4

0.05

1.0

9.0

8.0

2.0

2.0

4.0

1.0

1.0

4.0

2.0

4.0

98.8 


\section{III.2. Weight loss study}

\section{III.2.1. Effect of inhibitor concentration}

Table 2 shows the results obtained from weight loss measurements for mild steel in 1.0 M HCl solutions in the absence and presence of different concentrations of inhibitor (Oil Eucalyptus). It has been observed from the results that the $\eta \mathrm{WL} \%$ of Oil Eucalyptus increases from $86 \%$ to $93 \%$ with the increase in inhibitor concentration from 0.25 to $1 \mathrm{~g} / \mathrm{L}$. Indeed, corrosion rate values of MS decreases from 0.112 to $0.061 \mathrm{mg} / \mathrm{cm}^{2} \cdot \mathrm{h}$ on the addition of 0.25 to $1 \mathrm{~g} / \mathrm{L}$ of Oil Eucalyptus. The increase in efficiency from $86 \%$ to $93 \%$ may be due to the blocking effect of the surface by both adsorption and film formation mechanisms, which decreases the effective area of corrosion attack.

The results confirm that Oil Eucalyptus is an efficient corrosion inhibitor eco-friendly, which gives efficiency values as high as $93 \%$ in temperature $308 \mathrm{~K}$. The inhibiting performance exhibited by the Commercial oil of Eucalyptus may be due to the presence of the Compounds organic (see Table 1) which makes it adsorb quickly on the mild steel surface, thus forming an insoluble stable film on the surface of the mild steel.

Table 2: Weight loss values of various concentrations of Oil Eucalyptus in $1.0 \mathrm{M} \mathrm{HCl}$ solution.

\begin{tabular}{cccc}
\hline $\begin{array}{c}\text { Concentrations } \\
(\mathbf{g} / \mathbf{L})\end{array}$ & $\begin{array}{c}\boldsymbol{C}_{\mathbf{R}} \\
\left(\mathbf{m g} / \mathbf{c m}^{\mathbf{2}} \cdot \mathbf{h}\right)\end{array}$ & $\boldsymbol{\eta}_{\mathbf{W L}}(\boldsymbol{\%})$ & $\boldsymbol{\theta}$ \\
\hline $\mathrm{HCl}(1 \mathrm{M})$ & 0.82 & - & - \\
\hline $0.25 \mathrm{~g} / \mathrm{L}$ & 0.112 & 86 & 0.86 \\
$0.50 \mathrm{~g} / \mathrm{L}$ & 0.097 & 88 & 0.88 \\
$1.00 \mathrm{~g} / \mathrm{L}$ & 0.061 & 93 & 0.93 \\
\hline
\end{tabular}

\section{III.3. Adsorption isotherm}

Metal surface providing us several information about the adsorption mechanism of the inhibitors on the surface by studying the relationship between the concentration and the surface coverage. Many isotherms are employed to fit the experimental data such as the Langmuir, Freundlich, Temkin, Dubinin-Radushkevich, Frumkin, and BET (Brunauer, Emmett and Teller) isotherms.

It is found that the adsorption of our studied green inhibitor on steel surface obeys the Langmuir adsorption isotherm equation [17]:

$$
\frac{C}{\theta}=\frac{1}{K}+C
$$


Where $C$ is the concentration of inhibitor, $K$ the adsorption equilibrium constant, and $\theta$ is the surface coverage.

Plots of $C / \theta$ against $C$ yield straight lines as shown in Figure 1, and the corresponding linear regression parameters are listed in Table 3. Both linear correlation coefficient (r) and slope are close to 1, indicating the adsorption of commercial oil of Eucalyptus green inhibitor on mild steel surface obeys Langmuir adsorption isotherm.

Furthermore, the adsorption equilibrium constant $(K)$ is related to the standard free energy $\Delta G^{0}$ by the following equation:

$$
\Delta G_{\mathrm{ads}}^{0}=-R T \ln (55.5 K)
$$

Where $\mathrm{R}$ is the gas constant $\left(8.314 \mathrm{~J} \cdot \mathrm{K}^{-1} \mathrm{~mol}^{-1}\right), T$ the absolute temperature $(\mathrm{K})$, and the value 55.5 is the concentration of water in the solution.

Generally, at values of $\Delta G_{\text {ads }}^{0}$ up to $-20 \mathrm{~kJ} / \mathrm{mol}$, the types of adsorption were regarded as physisorption, the inhibition acts due to the electrostatic interactions between the charged molecules and the charged metal, while values around $-40 \mathrm{~kJ} / \mathrm{mol}$ or smaller are associated with chemisorption as a result of sharing or transfer of electrons from organic molecules to the metal surface to form a coordinate type of bond (chemisorption) $[18,19]$.

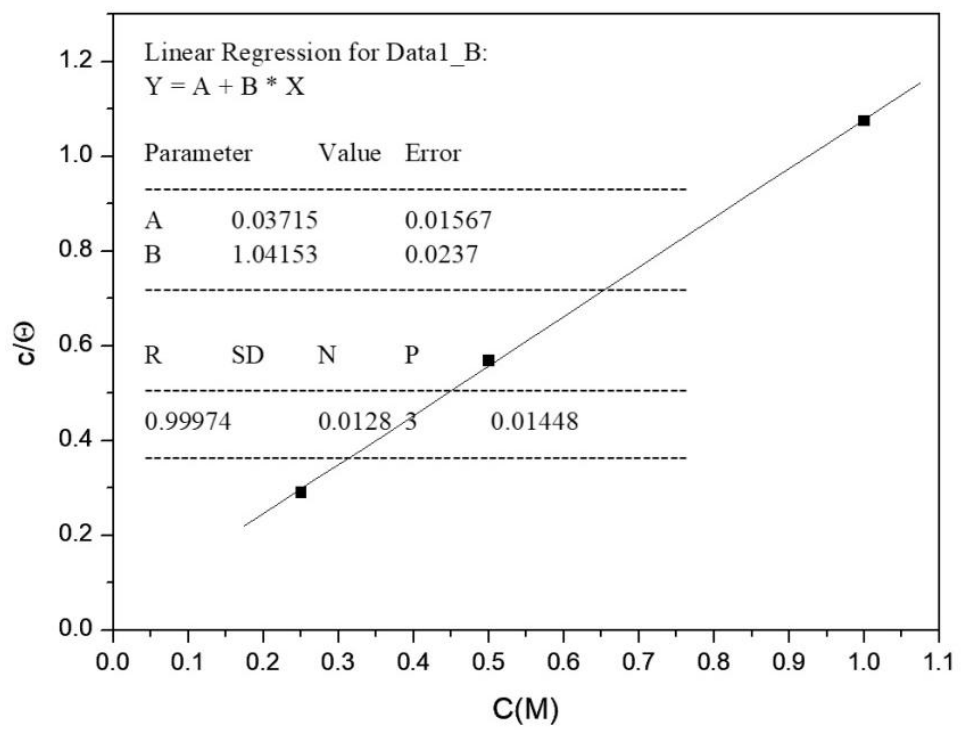

Figure 1. The Langmuir adsorption isotherm plots for the adsorption of Commercial oil of Eucalyptus in $1.0 \mathrm{M} \mathrm{HCl}$ on the surface of mild steel.

Then according to Equation (2), we calculated the $\Delta G_{\mathrm{ads}}^{0}=-18.71 \mathrm{~kJ} / \mathrm{mol}$. Therefore it can be concluded that the adsorption of the Commercial oil of Eucalyptus on the mild steel surface is mainly the physisorption. 
Table 3. Thermodynamics parameters for adsorption off inhibitor Commercial oil of Eucalyptus on the mild steel surface in $1 \mathrm{M} \mathrm{HCl}$.

\begin{tabular}{ccccc}
\hline Inhibitor & Linear correlation & Slope & $\boldsymbol{K}$ & $\begin{array}{c}\Delta \boldsymbol{G}^{\mathbf{0}} \\
\left(\mathbf{k J} \cdot \mathbf{m o l}^{\mathbf{1}} \mathbf{)}\right.\end{array}$ \\
\hline $\begin{array}{c}\text { Commercial oil of } \\
\text { Eucalyptus }\end{array}$ & 0.999 & 1.041 & 26.91 & -18.71 \\
\hline
\end{tabular}

\section{III.4. Influence of temperature}

To investigate the mechanism of inhibition and to determine the thermodynamic functions of the corrosion process, gravimetric test of mild steel in $1 \mathrm{M} \mathrm{HCl}$ were determined at various temperatures $(318-348 \mathrm{~K})$ in the absence and presence of $10^{-3} \mathrm{M}$ of Commercial oil of Eucalyptus.

The effect of temperature on the inhibition efficiency of the Commercial oil of Eucalyptus is shown in Table 4. An increase in temperature from 318-348 K resulted in an increase in the corrosion rate, probably as a result of desorption of inhibitor molecules from the metal surface [20].

Table 4. Weight loss values of Commercial oil of Eucalyptus at various temperatures in $1.0 \mathrm{M} \mathrm{HCl}$ solution.

\begin{tabular}{|c|c|c|c|}
\hline $\begin{array}{c}\text { Temperature } \\
\text { (K) }\end{array}$ & Inhibitor & $\begin{array}{c}C_{\mathrm{R}} \\
\left(\mathrm{mg} / \mathrm{cm}^{2} \cdot \mathbf{h}\right)\end{array}$ & $\begin{array}{l}\eta_{W L} \\
(\%)\end{array}$ \\
\hline \multirow{2}{*}{318} & $\mathrm{HCl} 1 \mathrm{M}$ & 2.2541 & - \\
\hline & Commercial oil of Eucalyptus & 0.4403 & 80 \\
\hline \multirow{2}{*}{328} & $\mathrm{HCl} 1 \mathrm{M}$ & 4.2581 & \\
\hline & Commercial oil of Eucalyptus & 1.0054 & 76 \\
\hline \multirow{2}{*}{338} & $\mathrm{HCl} 1 \mathrm{M}$ & 7.189 & \\
\hline & Commercial oil of Eucalyptus & 2.2723 & 68 \\
\hline \multirow{2}{*}{348} & $\mathrm{HCl} 1 \mathrm{M}$ & 9.9806 & \\
\hline & Commercial oil of Eucalyptus & 3.5878 & 64 \\
\hline
\end{tabular}

The effect of temperature on the corrosion inhibition efficiency of the Commercial oil of Eucalyptus can be best represented by Arrhenius equation which represents the natural $\log$ arithm of corrosion rate $\left(\ln C_{\mathrm{R}}\right)$ as a linear function of $1 / T$ :

$$
\ln C_{\mathrm{R}}=\left(E_{\mathrm{a}} / R T\right)+A
$$


Where $C_{\mathrm{R}}$ is the corrosion rate, $E_{\mathrm{a}}$ is the apparent activation energy, and $A$ is the preexponential factor. The Arrhenius plots of $\ln C_{\mathrm{R}}$ versus $1 / T$ for the blank and optimum concentration of inhibitor Commercial oil of Eucalyptus give a straight line and a slope equal to $-E_{\mathrm{a}} / \mathrm{R}$ shown in Figure 2, from which the values of $E_{\mathrm{a}}$ for the inhibited corrosion reaction of mild steel have been calculated and recorded in Table 5.

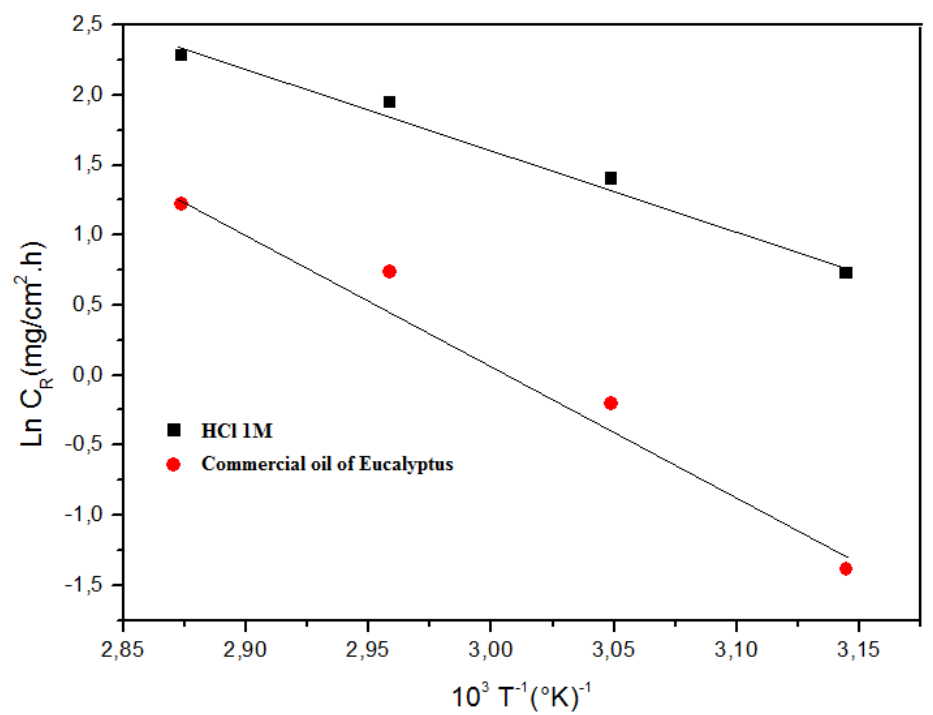

Figure 2. Arrhenius plots for mild steel corrosion rates $\operatorname{Ln}\left(C_{\mathrm{R}}\right)$ versus $1 / T$ in $1.0 \mathrm{M} \mathrm{HCl}$ in absence and in presence of optimum concentration of inhibitor commercial oil of Eucalyptus.

In 1.0 M HCl solution, the addition of inhibitor (Commercial oil of Eucalyptus) leads to an increase in the apparent activation energy to value greater than that of the uninhibited solution. The results show that the addition of inhibitor decreases metal dissolution in $1.0 \mathrm{M} \mathrm{HCl}$ medium. On the other hand, the increase in the apparent activation energy may be interpreted as physical adsorption that occurs in the first stage [21,22].

Table 5. The values of activation parameters for mild steel in $1.0 \mathrm{M} \mathrm{HCl}$ in the absence and presence of $10^{-3} \mathrm{M}$ of inhibitor commercial oil of Eucalyptus.

\begin{tabular}{cc}
\hline Inhibitor & $\boldsymbol{E}_{\mathbf{a}}(\mathbf{J} / \mathbf{m o l})$ \\
\hline HCl 1 M & 48.13 \\
\hline Commercial oil of Eucalyptus & 80.89 \\
\hline
\end{tabular}




\section{III.5. Potentiodynamic polarization curves}

The polarization curves of the mild steel in $1 \mathrm{M} \mathrm{HCl}$ in the absence and presence of inhibitor commercial oil of Eucalyptus at different concentrations at $308 \mathrm{~K}$ are shown in Figure 3. Corrosion potential $\left(E_{\text {corr }}\right)$, corrosion current $\left(I_{\text {corr }}\right)$, Tafel cathodic slopes $\left(\beta_{\mathrm{c}}\right)$ and percentage inhibition efficiency $(E \%)$ are shown in Table 6.

The relationship determines Inhibition efficiency $(E \%)$ :

$$
E(\%)=\frac{I_{\text {corr }}^{0}-I_{\text {corr }}}{I_{\text {corr }}^{0}} \times 100
$$

Where $I_{\text {corr }}^{0}$ and $I_{\text {corr }}$ are uninhibited and inhibited corrosion current densities, respectively. Under the experimental conditions performed, the cathodic branch represents the hydrogen evolution reaction, while the anodic branch represents the iron dissolution reaction.

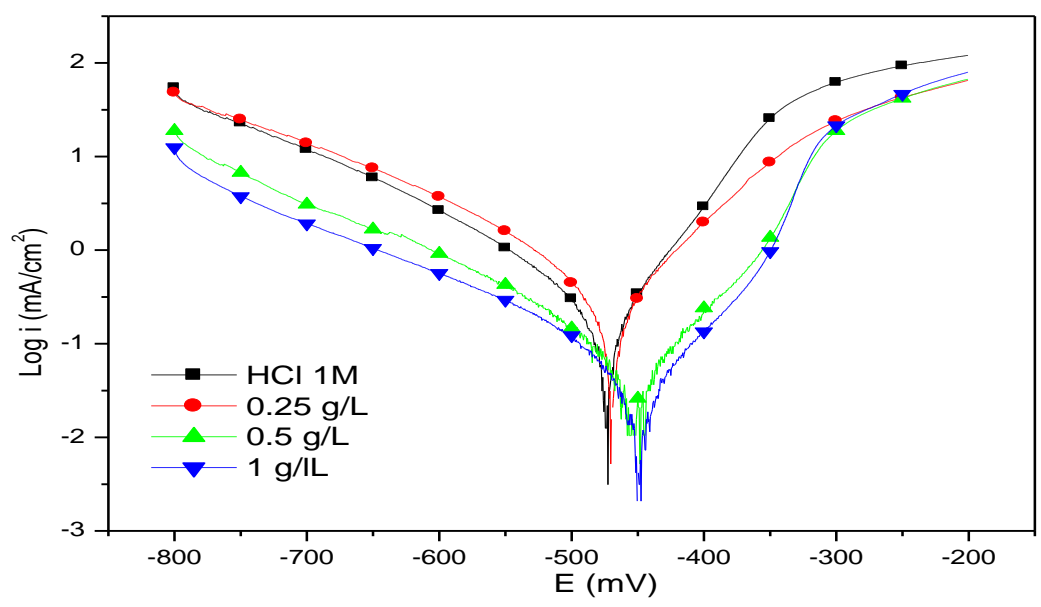

Figure 3. Tafel polarization curves in in $\mathrm{HCl} 1 \mathrm{M}$ with and without inhibitor commercial oil of Eucalyptus at different concentrations.

Table 6. Corrosion parameters obtained by electrochemical measurements for mild steel in $1 \mathrm{M} \mathrm{HCl}$ at various concentrations of inhibitor commercial oil of Eucalyptus.

\begin{tabular}{cccccc}
\hline $\begin{array}{c}\text { Inhibitor } \\
\text { concentration }\end{array}$ & $\begin{array}{c}-\boldsymbol{E}_{\text {corr }} \\
(\mathbf{V})\end{array}$ & $\begin{array}{c}-\boldsymbol{\beta}_{\mathbf{c}} \\
(\mathbf{m V / d e c})\end{array}$ & $\begin{array}{c}\boldsymbol{\beta}_{\mathbf{a}} \\
(\mathbf{m V / d e c})\end{array}$ & $\begin{array}{c}\boldsymbol{I}_{\text {corr }} \\
\left(\boldsymbol{\mu} \mathbf{A} / \mathbf{c m}^{2}\right)\end{array}$ & $\begin{array}{c}\boldsymbol{E} \\
(\boldsymbol{\%})\end{array}$ \\
\hline $\mathrm{HCl} 1 \mathrm{M}$ & 0.46 & 149 & 61 & 3618 & - \\
\hline $0.25 \mathrm{~g} / \mathrm{L}$ & 0.47 & 165 & 89 & 649 & 82 \\
$0.5 \mathrm{~g} / \mathrm{L}$ & 0.44 & 170 & 76 & 394 & 89 \\
$1 \mathrm{~g} / \mathrm{L}$ & 0.43 & 193 & 60 & 167 & 95 \\
\hline
\end{tabular}


The geometric blocking effect of the adsorbed inhibitory species, the blocking effect of active sites by the adsorbed inhibitory species and the electro-catalytic effect of the inhibitor or its reaction products, are the three classifications of inhibition modes Inhibitors [23].

The first mode of the inhibitory effect, comes from the reduction of the reaction zone on the surface of the corrosive metal, whereas the other two modes are due to changes in the mean energy barriers of activation of the reactions anodic and cathodic properties of the corrosion process.

The slight changes in the Tafel cathodic slope $\left(\beta_{c}\right)$ with the addition of of inhibitor commercial oil of Eucalyptus, are due to the inhibitory action that occurred by simple blocking of the cathodic sites available on the metal surface $[24,25]$. This leads to a reduction in the exposed surface area necessary for the evolution of hydrogen and the lowering of the dissolution rate with the increasing inhibitor concentration (Table 6).

\section{III.6. Electrochemical impedance spectroscopy}

In order to discuss the inhibition performance and mechanism of commercial oil of Eucalyptus, the EIS of mild steel specimens immersed in the absence and presence of inhibitor with various concentrations were displayed in Figure 4.

EIS is an important tool for determining, double-layer capacitance, $C_{\mathrm{dl}}$ and resistance to transfer Rt. The study of the change of these parameters as a function of time or with respect to other variables gives us important information on the kinetics of the corrosion process involved. The impedance measurements were carried out using AC signals of amplitude $10 \mathrm{mV}$ peak to peak, the open circuit potential using Tacussel Radiometer PGZ 301 Frequency Response Analyzer in a frequency range of $100 \mathrm{kHz}$ to $10 \mathrm{mHz}$.

Figure 4 show the electrochemical impedance graph for mild steel in the $1 \mathrm{M} \mathrm{HCl}$ solution in the absence and presence of various concentrations of commercial oil of Eucalyptus. The impedance data of the EIS experiments carried out in the absence and presence of different concentrations of the oil studied are summarized in Table 7.

The charge transfer resistance, $R_{\mathrm{t}}$ values are calculated from the difference in impedance at lower and higher frequencies, as suggested by several authors [26-31].

The inhibition efficiency $E(\%)$ was estimated from the charge transfer resistance measured, $R_{\mathrm{ct}}$, using the following equation:

$$
E \%=\left(\left(R_{\mathrm{ct}}-R_{\mathrm{ct}}^{0}\right) / R_{\mathrm{ct}}\right) \times 100
$$

Where $R_{\mathrm{ct}}^{0}$ and $R_{\mathrm{ct}}$ are the charge-transfer resistance values in the absence and presence of the inhibitor, respectively. All electrochemical measurements were done in unstirred and deaerated solutions. 
It is found that $R_{\mathrm{ct}}$ values increase with the increase of Commercial oil of Eucalyptus concentrations, indicating an insulated adsorption layer's formation.

$R_{\mathrm{ct}}$ values increased and $C_{\mathrm{dl}}$ values decreased with increasing inhibitor concentration. These results indicate a decrease in the active surface area caused by the adsorption of the inhibitors on the mild steel surface and this suggests that the corrosion process is hampered. The best result for the inhibition efficiency of inhibitor commercial oil of Eucalyptus was obtained at a concentration of $0.1 \mathrm{~g} / \mathrm{L}$, with a yield of $89 \%$.

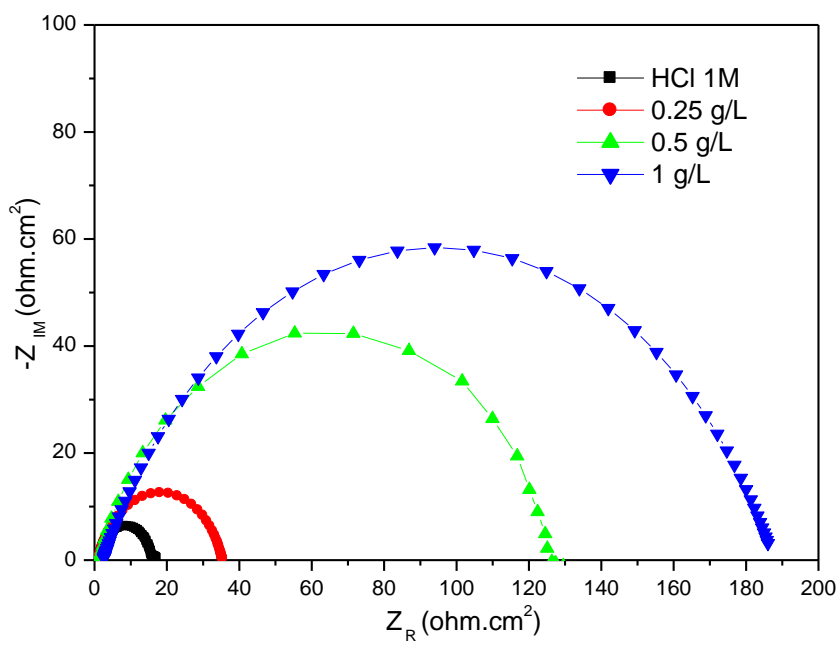

Figure 4. Nyquist plots in absence and presence of different concentrations of inhibitor commercial oil of Eucalyptus in $\mathrm{HCl} 1 \mathrm{M}$.

Table 7. Corrosion parameters obtained by impedance measurements for mild steel in $1 \mathrm{M} \mathrm{HCl}$ at various concentrations of commercial oil of Eucalyptus.

\begin{tabular}{cccc}
\hline $\begin{array}{c}\text { Inhibitor } \\
\text { concentration }\end{array}$ & $\begin{array}{c}\boldsymbol{R}_{\mathbf{c t}} \\
\left(\mathbf{O h m} \cdot \mathbf{c m}^{2}\right)\end{array}$ & $\begin{array}{c}\boldsymbol{C}_{\mathbf{d l l}} \\
\left(\boldsymbol{\mu} \mathbf{F} / \mathbf{c m}^{\mathbf{2}}\right)\end{array}$ & $\begin{array}{c}\boldsymbol{E} \\
(\boldsymbol{\%})\end{array}$ \\
\hline $\mathrm{HCl} 1 \mathrm{M}$ & 17 & 200 & - \\
\hline $0.25 \mathrm{~g} / \mathrm{L}$ & 35 & 139 & 46 \\
$0.5 \mathrm{~g} / \mathrm{L}$ & 127 & 98 & 84 \\
$1 \mathrm{~g} / \mathrm{L}$ & 185 & 63 & 89 \\
\hline
\end{tabular}

\section{Conclusion}

Commercial oil of Eucalyptus exhibits a considerable inhibitive effect on mild steel corrosion in $1.0 \mathrm{M} \mathrm{HCl}$ solution. The polarization plots indicate that the studied Eucalyptus 
inhibitor affects both the anodic metal dissolution, and the cathodic hydrogen evolution acting as a mixed type inhibitor. The impedance measurements show that the charge transfer resistance $\left(R_{\mathrm{ct}}\right)$ and the double layer capacitance $\left(C_{\mathrm{dl}}\right)$ have opposite concentration relationships ( $R_{\mathrm{ct}}$ increases, while $C_{\mathrm{dl}}$ decreases with the increase in the Eucalyptus inhibitor concentration). All the results that obtained from the electrochemical studies show an excellent agreement with the weight loss measurements.

\section{References}

1. S. Rajendran, R. Srinivasan, R. Dorothy, T. Umasankareswari and A. Al-Hashem, Int. J. Corros. Scale Inhib., 2019, 8, no. 3, 437-479. doi: 10.17675/2305-6894-2019-8-3-1

2. H.M. Refaat, A.A. Moneer and O.M. Khalil, Arch. Pharmacal Res., 2004, 27, 1093-1098.

3. S. Attabi, M. Mokhtari, Y. Taibi, I. Abdel-Rahman and B. Hafez, J. Bio. Tribo Corros. 2019, 5, 2. doi: $10.1007 / \mathrm{s} 40735-018-0193-5$

4. P. Udhayakala, T.V. Rajendiran and S. Gunasekaran, J. Chem., Biol. Phys. Sci., 2012, 2, 1151-1165.

5. H. Elmsellem, T. Harit, A. Aouniti and F. Malek, Prot. Met. Phys. Chem. Surf., 2015, 51, 873-884.

6. S.O. Adejo, M.M. Ekwenchi, J.U. Ahile, J.A. Gbertyo, B. Ishua and A. Akombor, J. Corros. Sci. Eng., 2014, 17, 1-13.

7. D. Jeroundi, S. Chakroune, H. Elmsellem, E.M. ElHadrami, A. Ben-Tama, A. Elyoussfi and B. Hafez, J. Mater. Environ. Sci., 2017, 5, 1116-1127.

8. L.Y.S. Helen, A.A. Rahim, B. Saad, M.I. Saleh and P.B. Raja, Int. J. Electrochem. Sci., 2014, 9, no. 2, 830-846.

9. S. Kumar, D.G. Ladha, P.C. Jha and N.K. Shah, Int. J. Corros., 2013, 10, 819643. doi: $\underline{10.1155 / 2013 / 819643}$

10. H. Elmsellem, Y.El Ouadi, M. Mokhtari, H. Steli, A. Aouniti, A.M. Almehdi, I. AbdelRahman and H.S. Kusuma, J. Chem. Technol. Metall., 2019, 54, 742-749.

11. M. Khasanah, H. Darmokoesoemo, L. Kustyarini, Y. Kadmi and H. S. Kusuma, Results Phys., 2017, 7, 1781-1791. doi: 10.1016/j.rinp.2017.05.015

12. S. Rajendran, M. Agasta, R. Bama Devi, B. Shymala Devi, K. Rajam and J. Jeyasundari, Zast. Mater., 2009, 50, no. 2, 77-84 (in Serbian).

13. H. Elmsellem, N. Basbas, A. Chetouani and A. Aouniti, Port. Electrochim. Acta, 2014, 2, 77-108.

14. P. Nithyadevi, J. Sathiyabama, S. Rajendran, R.J. Rathish and S. Santhana Prabha, Int. J. Nano Corr. Sci. Engg., 2015, 2, 1-9.

15. M. Ramezanzadeh, G. Bahlakeh, Z. Sanaei and B. Ramezanzadeh, J. Mol. Liq., 2018, 272, 120-136. 
16. H. Elmsellem, A. Aouniti, H. Bendaha, T. Benhadda, A. Chetouani and I. Warad, Phys. Chem. News, 2013, 70, 84.

17. M.A. Asaad, M. Ismail, M.M. Tahir, G.F. Huseien, P.B. Raja and Y.P. Asmara, Constr. Build. Mater., 2018, 188, 555-568.

18. Ya.G. Avdeev, Int. J. Corros. Scale Inhib., 2018, 7, no. 4, 460-497. doi: 10.17675/2305-6894-2018-7-4-1

19. R.G. Pearson, J. Am. Chem. Soc., 1988, 110, 7684-7690.

20. Z. Jamshidnejad, A. Afshar and M.A. Razmjoo Khollari, Int. J. Electrochem. Sci., 2018,13 , no. $12,12278-12293$.

21. O. Olawale, B.T. Ogunsemi J.O. Bello, P.P. Ikubanni, S.J. Ogundipe and T.S. Abayomi, Int. J. Mech. Eng. Technol., 2018, 9, no. 13, 1274-1285.

22. H. Elmsellem, M.H. Youssouf and A. Aouniti, Russ. J. Appl. Chem., 2014, 8, 744-753.

23. S. Abrishami, R. Naderi and B. Ramezanzadeh, Appl. Surf. Sci., 2018, 457, 487-496.

24. K.R. Ansari, S. Ramkumar, D.S. Chauhan, Md. Salman, D. Nalini, V. Srivastava and M.A. Quraishi, Int. J. Corros. Scale Inhib., 2018, 7, no. 3, 443-459. doi: 10.17675/2305-6894-2018-7-3-13

25. H. Elmsellem, H. Nacer, F. Halaimia, A. Aouniti, I. Lakehal, A. Chetouani and B. Hammouti, Int. J. Electrochem. Sci., 2014, 9, 5328-5351.

26. C. Verma, E.E. Ebenso and M.A. Quraishi, Int. J. Corros. Scale Inhib., 2018, 7, no. 4, 593-608. doi: 10.17675/2305-6894-2018-7-4-8

27. M.A. Asaad, M. Ismail, N.H.A. Khalid, G.F. Huseien and P.B. Raja, Jurnal Teknologi, 2018, 80, 53-59.

28. V. Sribharathy, K. Kavipriya, N. Vellachi and K. Vijaya, Int. J. Mech. Eng. Technol., 2018, 9, 1614-1621.

29. A. Berrani, H. Benassaoui, M. Zouarhi, A. Alrhorfi, N. Hajjaji and R. Bengueddour, Anal. Bioanal. Electrochem., 2018, 10, 1299-1316.

30. T.K. Bhuvaneswari, V.S. Vasantha and C. Jeyaprabha, Silicon, 2018, 10, 1793-1807.

31. M. Filali, E.M. El Hadrami, A. Ben-tama, B. Hafez, I. Abdel-Rahman, A. Harrach, H. Elmsellem, B. Hammouti, M. Mokhtari, SE. Stiriba and M. Julve, Int. J. Corros. Scale Inhib., 2019, 8, no. 1, 93-109. doi: $\underline{\text { 10.17675/2305-6894-2019-8-1-9 }}$ 